\title{
Links between Western Pacific Subtropical High and vegetation growth in China
}

\author{
HUANG Mei ${ }^{1}, \mathrm{HAO} \mathrm{Man}^{1,2}$, WANG Shaoqiang ${ }^{1,2}, \mathrm{DAN} \mathrm{Li}^{3}$, GU Fengxue ${ }^{4}$, \\ WANG Zhaosheng ${ }^{1}$, GONG He ${ }^{1}$
}

1. Key Laboratory of Ecosystem Network Observation and Modeling, Institute of Geographic Sciences and Natural Resources Research, CAS, Beijing 100101, China;

2. University of Chinese Academy of Sciences, Beijing 100049, China;

3. START Temperate East Asia Regional Center and Key Laboratory of Regional Climate-Environment for Temperate East Asia, Institute of Atmospheric Physics, CAS, Beijing 100029, China;

4. Key Laboratory of Dryland Agriculture, Ministry of Agriculture, Institute of Environment and Sustainable Development in Agriculture, Chinese Academy of Agricultural Sciences, Beijing 100081, China

\begin{abstract}
There is a lack of simple ways to predict the vegetation responses to the East Asian Monsoon (EAM) variability in China due to the complexity of the monsoon system. In this study, we found the variation of the Western Pacific Subtropical High (WPSH), which is one of the major components of the EAM, has a profound influence on the vegetation growth in China. When the WPSH is located more to the west of its climate average, the eastern and northwestern parts experience increased yearly-averaged normalized difference vegetation index (NDVI) and gross primary productivity (GPP) by $0.3 \%-2.2 \%$, and $0.2 \%-2.2 \%$, respectively. In contrast, when the WPSH is located more to the east of its climate average, the above areas experience decreased yearly-averaged NDVI and GPP by $0.4 \%$ to $1.6 \%$, and $1.3 \%$ to $4.5 \%$, respectively. The WPSH serves as a major circulation index to predict the response of vegetation to monsoon.
\end{abstract}

Keywords: East Asia monsoon; Western Pacific Subtropical High; normalized difference vegetation index (NDVI); gross primary productivity (GPP); China

\section{Introduction}

The Western Pacific Subtropical High (WPSH), which occupies about $20 \%-25 \%$ of the Northern Hemispheric surface, is a major permanent climate system (Zhou et al., 2009). It controls the movement of weather systems and water vapor transportation in the subtropical areas and often cause large-scale weather extremes. It has obvious seasonal cycles and remarkable variations in location and intensity on various timescales (Liu and $\mathrm{Wu}, 2004$ ). Its variations in intensity, structure, and location strongly influence the climate in China, as it is closely associated with the summer monsoon in East Asia and the winter monsoon in north-

Received: 2017-02-06 Accepted: 2017-04-18

Foundation: National Key Research and Development Program of China, 2017YFC0503905; National Natural Science Foundation of China, No.41671101, No.41630532, No.41575091

Author: Huang Mei (1968-), specialized in the influence of climate change on ecosystems. E-mail: huangm@igsnrr.ac.cn 
ern China (Huang et al., 1985; Yang and Sun, 2003; Jiang et al., 2011). The spatial and temporal pattern of precipitation over eastern China depends to a large degree on the lateral displacement of the WPSH (Huang and Wang, 1985). Many studies have investigated the mechanism of the WPSH and its relationship with the summer precipitation and temperature in China (Sun and Ying, 1999; Lu 2002; Yang and Sun, 2003; Liu and Wu, 2004; Zhou and $\mathrm{Yu}, 2005)$. However, fewer studies have considered its impacts on the vegetation growth in China.

The trend of vegetation growth in China is thought to be driven by monsoon. Fu and Wen (1999) found the spatial and temporal variations of NDVI in East Asia are highly correlated with the variations in monsoon rainfall. Zhang et al. (2002) found the abrupt transition of the monsoon precipitation causes the seasonal variations of leaf area index (LAI) in eastern China. Previous studies on the vegetation-monsoon relationship in China depend much on the monsoon index. As the EAM system involves complex interactions among tropical, subtropical, and mid-latitude weather and climate systems, as well as the land-atmosphere-ocean interactions at various spatial and temporal scales, it is difficult to quantify the monsoon and its variation. Some indices, such as Webster and Yang Index (Webster and Yang, 1992), Monsoon Hadley Circulation Index (Goswami et al., 1999), Convection Index (Wang and Fan, 1999), Guo Index (Guo, 1983), Dynamical Normalized Seasonality Index (Li and Zeng, 2002), have notable differences which have led to discrepancies in the vegetation-monsoon relationship studies. For example, Jiang et al. (2013) reported a strong monsoon corresponds to positive net primary productivity (NPP) anomalies in southern China by using the Dynamical Normalized Seasonality Index while Li et al. (2015) found a strong monsoon corresponds to negative NPP anomalies in southern China by using the Guo Index. In general, there is a lack of simple methods for predicting the influences of the monsoon climate on vegetation growth. Due to the major influences of the WPSH on China's weather and climate over vast areas, it is important to better understand the links between the WPSH activities and vegetation growth in China, and to predict the vegetation responses to monsoon climate.

To quantify the spatial and temporal variations of vegetation growth, NDVI is used as a measure of the vegetation growth, greenness and cover (Tucker, 1979). NDVI has been widely used in studying the linkages between climate signals and vegetation dynamics, such as the relationships between El Niño/Southern Oscillation (Li and Kafatos, 2000; Anyamba et al., 2002; Li et al., 2016), North Atlantic Oscillation (Li et al., 2015), sea surface temperature (Los et al., 2001), West African monsoon (Jarlan et al., 2005; Nicholson et al., 2010) and regional NDVI. The changes of NDVI in China have been intensively studied before (Piao and Fang, 2003; Ding et al., 2015). Previous studies show yearly and seasonal NDVI changes in China are closely correlated with precipitation and temperature change (Zhang et al., 2006; Cui and Shi, 2010; Zhang et al., 2013; Zhou et al., 2014).

The strength of a WPSH is usually measured by the extent of the 5880 gpm contours. The China Meteorological Administration (CMA) has defined a series of indices for quantifying the WPSH activities, including the area $\left(I_{a}\right)$, intension $\left(I_{i}\right)$, position $\left(I_{r}\right)$, west boundary $\left(I_{w}\right)$ and north boundary $\left(I_{n}\right)$ indices which are routinely used for weather forecast and climate projection. In this study, we investigate the link between the WPSH indices and NDVI over China and the responsible mechanisms, focusing on the influences of the WPSH intensity 
and position anomalies. The objective of this study is to find a simple method for predicting and early warning the response of China's vegetation to the monsoon climate.

\section{Data sources and methods}

\subsection{Data sources}

The NDVI datasets used in this study are produced by the Global Inventory Monitoring and Modeling Studies (GIMMS) group using the AVHRR/NOAA series satellites (http:// glcf.umd.edu/data/gimms/). The GIMMS NDVI datasets are at a spatial resolution of $8 \mathrm{~km}^{2}$ and 15 day interval and have been corrected to minimize the effects of volcanic eruptions, solar angle and sensor errors and shifts and thus can be used as the indicators of vegetation growth (Piao et al., 2003). We derive monthly NDVI from two images for each month using the maximum value composite (MVC) method (Holben, 1986). Pixels with average annual NDVI less than 0.05 were considered as non-vegetated areas and thus removed. We consider average NDVI from March to May, June to August and September to November, and December to February as the spring, summer, autumn and winter NDVI, respectively. The yearly averages of the NDVI is the average of monthly NDVI over a year. The yearly GPP data are the outputs of the atmospheric-vegetation interaction model (AVIM2) which is at a spatial resolution of $10 \mathrm{~km}^{2}$ (Ji et al., 2008; Li et al., 2015).

The monthly air temperature and precipitation data of 670 meteorological stations are obtained from the CMA. The station data are interpolated to the $8 \mathrm{~km}^{2}$ spatial resolution using ANUSPLINE (Hutchinson, 1989). The yearly water vapor flux data and the geopotential height at $500 \mathrm{hPa}$ are from the NCEP/NCAR global reanalysis (Kalnay et al., 1996).

The monthly WPSH indices, including $I_{i}$ and $I_{w}$ are obtained from the CMA. They are derived from the geopotential height of $500 \mathrm{hPa}$. $I_{i}$ is defined by a weighted sum of the grid points at which the geopotential height greater than $5880 \mathrm{gpm}$ within the above region, with a weighting coefficient of 1 for geopotential height of $5880 \mathrm{gpm}$, of 2 for $5890 \mathrm{gpm}$, of 3 for $5900 \mathrm{gpm}$ etc. $I_{w}$ is the longitude of the WPSH western boundary of the $5880 \mathrm{gpm}$ isoline. $I_{a}$ is defined as the sum of grid points in which the geopotential height greater than $5880 \mathrm{gpm}$ within the region of $10^{\circ}-50^{\circ} \mathrm{N}$ and $180^{\circ}-110^{\circ} \mathrm{E}$, and $I_{r}$ is defined as the average latitude of the range from $110^{\circ} \mathrm{E}$ to $150^{\circ} \mathrm{E}$. Yearly $I_{i}$ and $I_{w}$ are the averages of the monthly $I_{i}$ and $I_{w}$. The growth season $I_{i}$ and $I_{w}$ are defined as averaged over the period of March to September.

\subsection{Methods}

We use $95 \%$ of the standard deviation as threshold to identify the high and low values for $I_{i}$ and $I_{w}$. In Equations (1) and (2), $I_{x}$ represents a growth season WPSH index, $\bar{I}_{x}$ is the mean of $I_{x}, n$ is the length of the $I_{x}$ time series and $i$ is year. If the growth season NDVI anomaly of year $i$ is greater (less) than $95 \%$ of the standard deviation of the growth season NDVI time series, then the year is defined as a high (low) WPSH year.

$$
\begin{gathered}
I_{x i}-\bar{I}_{x}>0.95 \sqrt{\frac{\sum_{i=1}^{n}\left(I_{x i}-\bar{I}_{x}\right)^{2}}{n}} \\
I_{x i}-\bar{I}_{x}<-0.95 \sqrt{\frac{\sum_{i=1}^{n}\left(I_{x i}-\bar{I}_{x}\right)^{2}}{n}}
\end{gathered}
$$


Composite analysis is to average the variables, such as NDVI, air temperature, precipitation, $500 \mathrm{hPa}$ geopotential height and water vapor fluxes, over high and low WPSH index years, respectively.

\section{Results}

\subsection{Seasonal and annual variations of WPSH}

Figure 1 shows the seasonal trajectory of WPSH, which exhibits a remarkable seasonal cycle. From January to April, the WPSH continues to extend westward, and then turns northeastward and reaches its northernmost position in August. After August, it turns southwestward and reaches its westernmost position in October. It then retreats southeastward to the sea. The WPSH intensity steadily increases from February to July and then decreases.

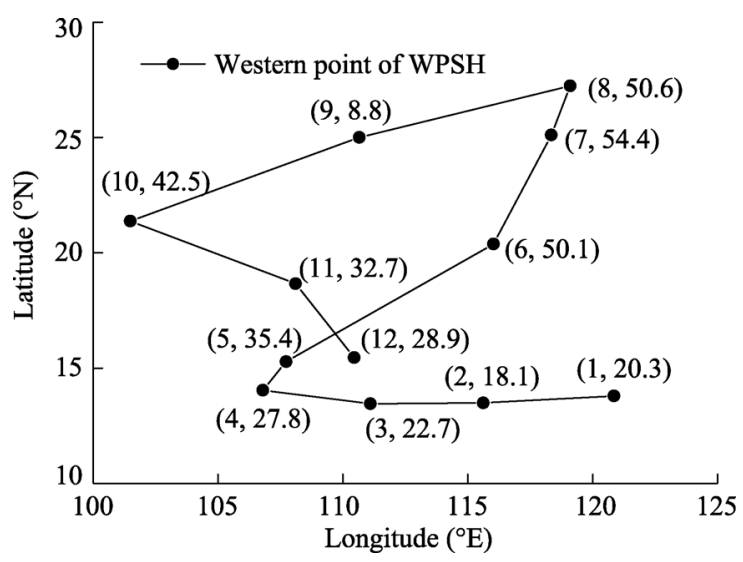

Figure 1 Seasonal trajectory of WPSH based on monthly means of $I_{w}$ and $I_{r}$ averaged over 1982-2010. The first number in the brackets denotes the number of month and the second number the monthly $I_{i}$ averaged over the study period.

Yearly $I_{i}$ is in the range of 13.2 and 68.5, and the year of 1994, 1995, 1998, 2005 and 2010 are identified as high $I_{i}$ years, while 1984, 1985, 1986, 1999 and 2000 are identified as low $I_{i}$ years. The high $I_{i}$ year corresponds to a strong WPSP, while the low to a weak WPSH. Yearly $I_{w}$ shifts between $93.3^{\circ} \mathrm{E}$ and $132.5^{\circ} \mathrm{E}$ with an average of $112.5^{\circ} \mathrm{E}$. The detected high $I_{w}$ years are 1984, 1985, 1986, 1989, 1999 and 2000, while the low $I_{w}$ years are 1983, 1987, 1995, 1998, 2003 and 2010. The high $I_{w}$ year corresponding to the WPSP is located in the east position, while the low to a west position.

\subsection{Variation of China's NDVI}

The spatial distribution of vegetation types in seven eco-regions and their regional mean yearly NDVI are shown in Figure 2. The seven eco-regions include Southwest China (SW), South China (SC), North China (NC), Inner Mongolia (IM), the Tibetan Plateau (TP) and North West China (NW). SW is dominated by tropical rain forest and subtropical evergreen forest, where the NDVI is the greatest. SC is mainly covered by subtropical evergreen forest and its NDVI is the second largest. NE is dominated by temperate forest and crops, while NC by crops with NDVI values of about 0.4 . IM and the TP are dominated by grassland with NDVI values of around 0.2 . NW mainly consists of desert, with sparse dry land vegetation 
of NDVI of around 0.14. Significant increasing trends are detected in the NDVI times series for SW, SC, NC and NW $(P<0.05)$.
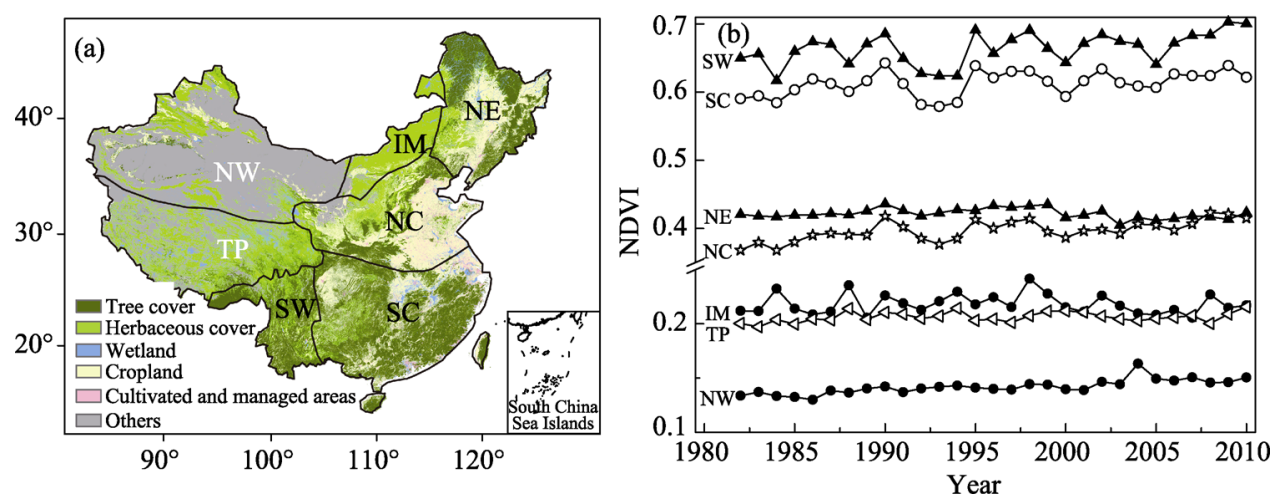

Figure 2 (a) Spatial distribution of vegetation types in the seven eco-regions of NE, IM, NW, NC, SC, TP and SW, representing Northeast China, Inner Mongolia, Northwest China, North China, Southeast China, Tibetan Plateau and Southwest China, respectively; (b) Regional mean yearly NDVI time series for eco-regions

\subsection{Response of China's NDVI to intensity of WPSH}

Figure 3a shows yearly $I_{i}$ is positively correlated with NDVI in most areas of NC and SC, but negatively in most areas of NE, NW and TP. Composite analysis shows yearly NDVI anomalies have almost opposite spatial patterns in strong and weak WPSH years (Figures $3 \mathrm{~b}$ and 3c). In strong WPSH years, regional average yearly NDIV anomalies are positive in all of the eco-regions except for SW, while in weak WPSH years, they are negative in most of the eco-regions except for NE and IM.
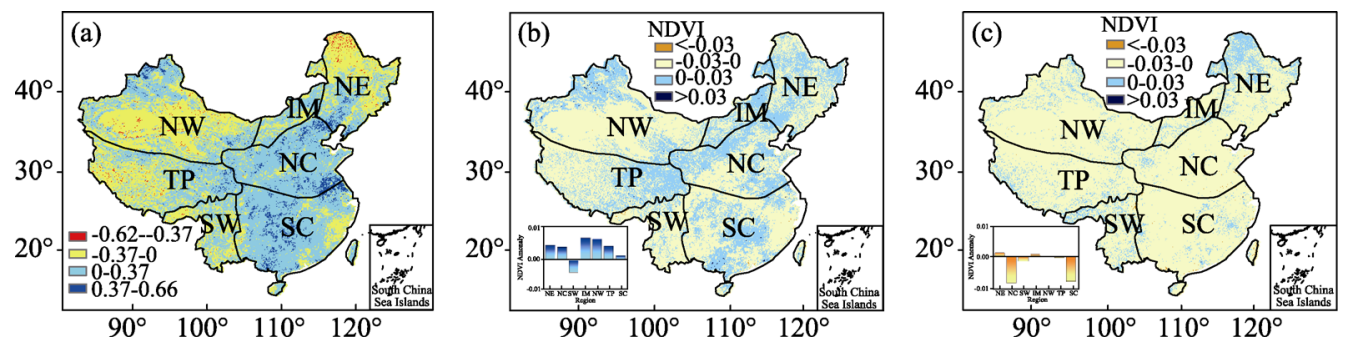

Figure 3 (a) Spatial distribution of correlation coefficient between yearly $I_{i}$ and NDVI; (b) Spatial distribution of yearly NDVI anomalies composite for high $I_{i}$ years; (c) As (b) but for low $I_{i}$ years. All the anomalies in this research are relative to the average of 1982-2010.

\subsection{Response of China's NDVI to zonal shifts of WPSH}

The zonal shifts of the WPSH have profound influences on China's NDVI. The spatial pattern of NDVI anomalies for low $I_{w}$ years are almost opposite to that for high $I_{w}$ years. Most of China's yearly NDVI anomalies are positive in the low $I_{w}$ years, but negative in the high $I_{w}$ years (Figures $4 \mathrm{a}$ and $4 \mathrm{~b}$ ). Regional averaged NDVI for NC, IM, NW and SC are about $3 \%, 0.4 \%, 1.3 \%$ and $1.6 \%$ lower than the 1982-2010 average for high $I_{w}$ years, respectively, but are $1.1 \%, 0.5 \%, 0.3 \%$ and $2.2 \%$ higher for low $I_{w}$ years, respectively.

However, not all areas in China are influenced by the variations of the WPSH. For example, average NDVI anomalies are negative in SW and TP for both high and low $I_{w}$ years, 
indicating NDVI in SW and TP are not influenced by the zonal shifts of the WPSH. Figures $4 \mathrm{a}$ and $4 \mathrm{~b}$ show NDVI anomalies are mostly negative in the southern part of NE in high $I_{w}$ years, but mostly positive in low $I_{w}$ years, which are consistent with NDVI anomalies in NC and IM during the two circulation patterns. However, the NDVI anomalies changes in the northern part of NE are opposite to that in the southern part of NE, indicating the northern part of NE may not be directly influenced by WPSH.

There is no simple one-to-one correspondence between the regional average NDVI and WPSH indices on annual time scale in most of the seven eco-regions. Only the regional NDVI average for NC and NW are significantly associated with $I_{a}$, with correlation coefficients of 0.38 and $0.48(P<0.05)$, which explains $14 \%$ to $23 \%$ of the NDVI variations, respectively. Previous studies on the NDVI-monsoon relationships find no significant correlation between annual NDVI and monsoon index (Fu and Wen, 1999).

To better understanding the impacts of WPSH on vegetation growth, we conducted composite analysis of the GPP difference in low and high $I_{w}$ years (Figures $4 \mathrm{c}$ and $4 \mathrm{~d}$ ). GPP is the amount of carbon assimilated by plants via photosynthesis, the process is believed to be influenced by climate and other environmental factors. The spatial pattern of model simulated GPP anomalies composite for low and high $I_{w}$ years agree well with the corresponding NDVI anomalies. Regional averaged GPP for NC, IM, NW and SC are about $1.8 \%, 3.3 \%$, $4.5 \%$ and $1.3 \%$ lower than the 1982-2010 average for the high $I_{w}$ years, respectively, but are $2.2 \%, 1.4 \%, 0.8 \%$ and $0.2 \%$ higher for the low $I_{w}$ years, respectively. The regional average
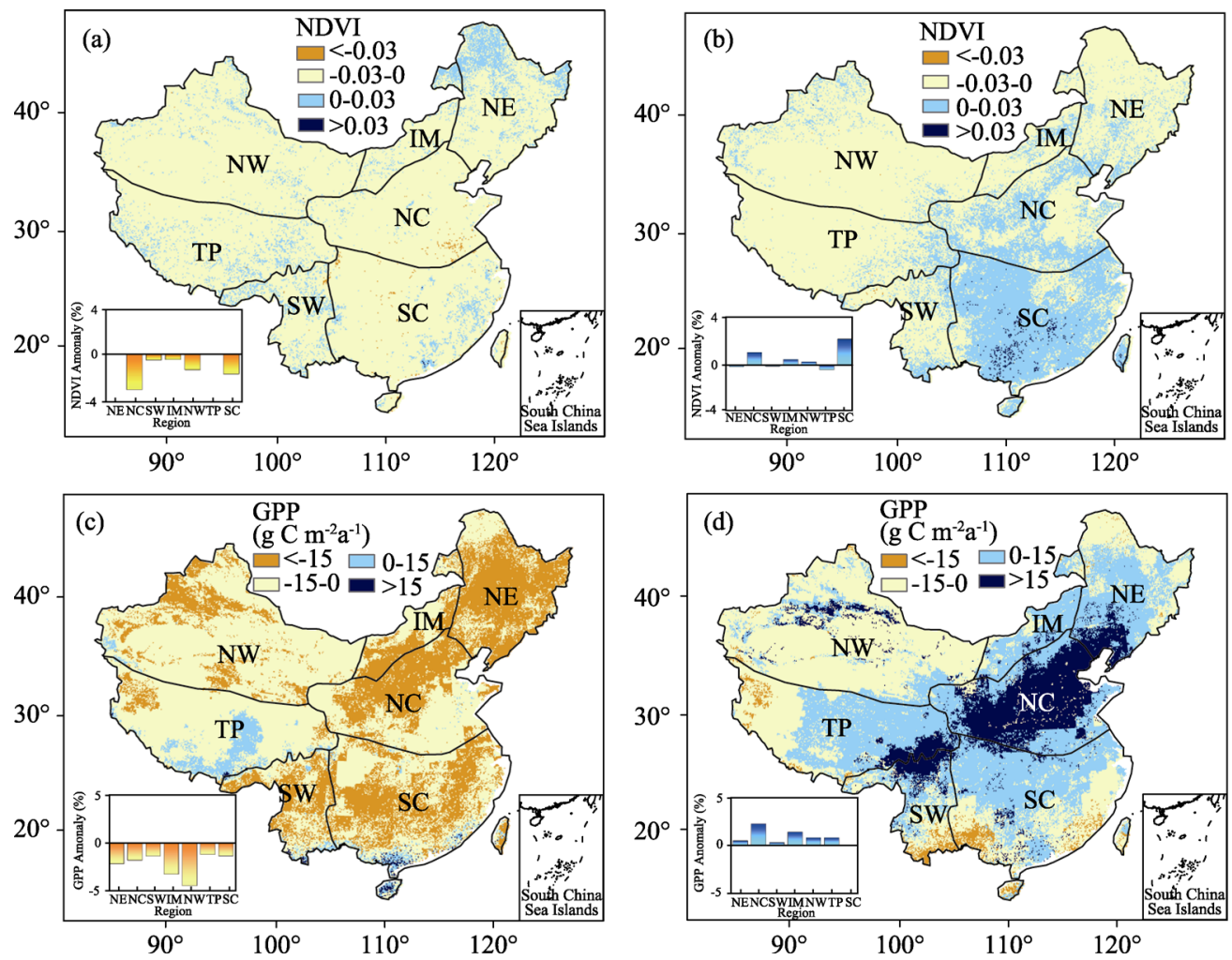

Figure 4 (a) Spatial distribution of yearly NDVI anomalies composite for high $I_{w}$ years; (b) As (a) but for low $I_{w}$ years; (c) Spatial distribution of yearly GPP anomalies composite for high $I_{w}$ years; (d) As (c) but for low $I_{w}$ years 
GPP for NE, NC, IM and NW are significantly correlated with $I_{a}$, while for SW, TP and SC with $I_{r}$. Regional GPP average for NW is also significantly correlated with $I_{w}$. These correlation coefficients are between $0.37-0.40$, indicting the variation of WPSH can explain $14 \%-16 \%$ GPP variations in China.

\section{Discussion}

\subsection{Impacts of anomalous zonal location of WPSH on water vapor transportation}

The NDVI pattern differences in the high and low $I_{w}$ years are associated with anomalous large-scale circulations. When the WPSH is in west position, the anomalous circulation pattern benefits the northeastward transport of the warmer tropical water vapor from the Bay of Bengal and the South China Sea along the northwestern flank of the WPSH. As Figure 5a shows, large quantities of water vapor are carried from the adjacent oceans to China. The convergence of the warmer tropical water vapor with the colder subtropical water vapor often results in heavy rainfall in eastern China. When the WPSH is in east position, it is relatively weak (Figure 5b). This circulation pattern suppresses the warmer water vapor transportation to east China, such that the vertically integrated water vapor anomalies are mostly negative over China.

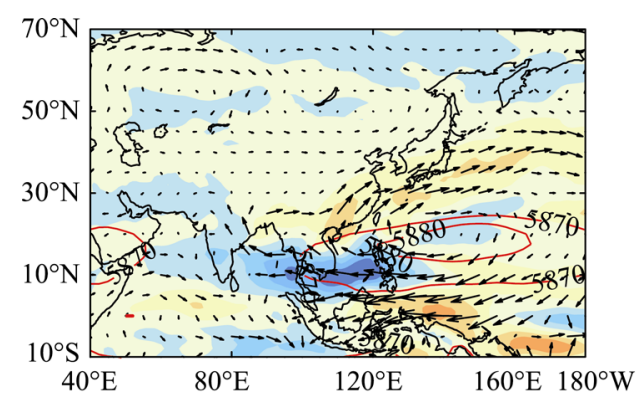

(a)

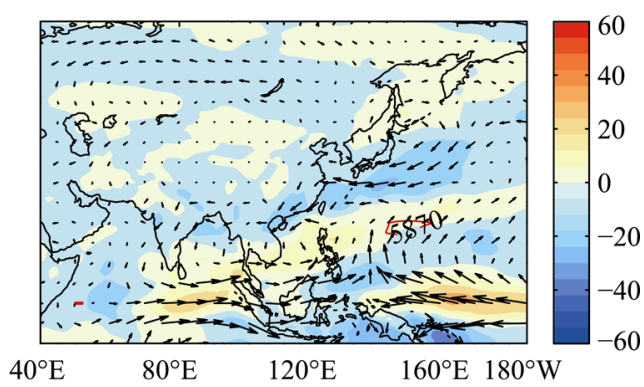

(b)

Figure 5 (a) The $500 \mathrm{hPa}$ geopotential height and vertically integrated water fluxes anomalies composite for low $I_{w}$ years; (b) As (a) but composite for high $I_{w}$ years

\subsection{Impacts of anomalous zonal location of WPSH on air temperature and precipitation}

The spatial patterns of yearly precipitation anomalies are generally consistent with that of the yearly average vertically integrated water vapor flux. The yearly precipitation anomalies are positive in most areas of China in low $I_{w}$ years, but negative in high $I_{w}$ years (Figures $6 \mathrm{a}$ and 6b). Positive temperature anomalies occurred in most area of SC, NC, NW, IM and NE in low $I_{w}$ years, while negative in high $I_{w}$ years (Figures $6 \mathrm{c}$ and $6 \mathrm{~d}$ ).

Regional average precipitation is $10.0 \%, 8.7 \%, 12.3 \%, 9.1 \%$ and $3.7 \%$ higher than 1982-2010 average for NE, NC, IM, NW and SC in low $I_{w}$ years, respectively, but are $0.9 \%$, $3.0 \%, 5.9 \%, 5.4 \%$ and $2.4 \%$ lower than the average in high $I_{w}$ years, respectively. Average temperature anomalies are in the range of $-0.2^{\circ} \mathrm{C}$ to $0.1^{\circ} \mathrm{C}$ for $\mathrm{NE}, \mathrm{NC}, \mathrm{IM}, \mathrm{NW}$ and $\mathrm{SC}$ in low $I_{w}$ years, while in the range of $-0.5^{\circ} \mathrm{C}$ to $-0.6^{\circ} \mathrm{C}$ in high $I_{w}$ years.

Figure 6e shows that NDVI is positively correlated with precipitation in IM and north- 
western NW. Anomalous WPSH enhances precipitation which causes NDVI to increase in the low $I_{w}$ years. However, it suppresses precipitation in the high $I_{w}$ years, so the NDVI decreases. The NDVI-precipitation relationship in the above areas can generally explain the NDVI differences between the low and high $I_{w}$ years.

NDVI is positively correlated with temperature in most areas of NC and SC (Figure 6f). The association of temperature and NDVI in the above regions can generally explain the
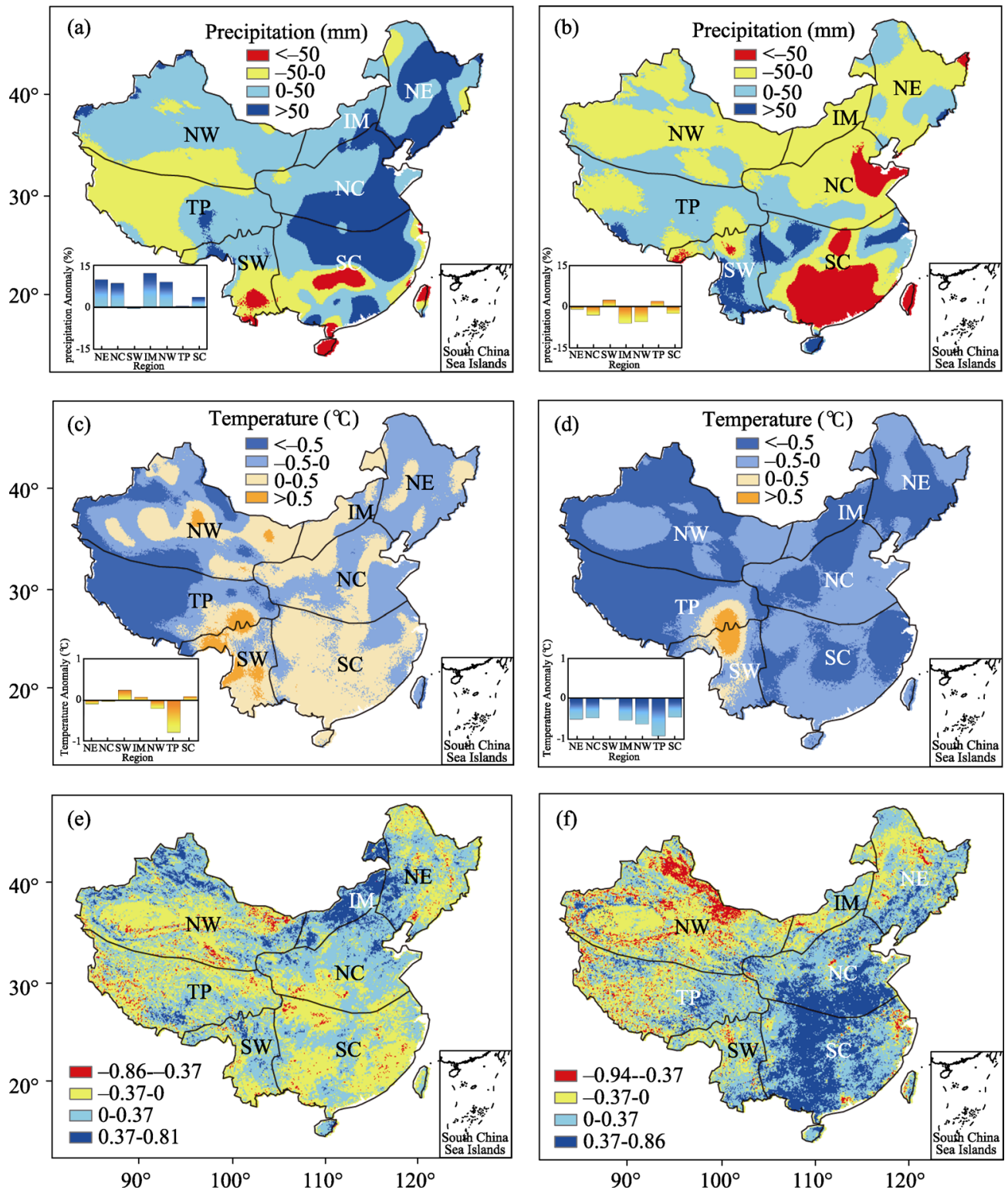

Figure 6 (a) Spatial pattern of yearly precipitation anomalies composite for low $I_{w}$ years; (b) As (a) but for high $I_{w}$ years; (c) Spatial pattern of yearly mean temperature anomalies composite for low $I_{w}$ years; (d) As (c) but for high $I_{w}$ years; (e) Spatial pattern of correlation coefficient between yearly NDVI and yearly precipitation; (f) As (e) but between yearly NDVI yearly mean temperature. 0.37 represents the threshold for $95 \%$ confidence level. 
NDVI variations during the two circulation patterns. Average temperature for low $I_{w}$ years is higher than that for high $I_{w}$ years in NC and SC, which cause higher NDVI in low $I_{w}$ years than in high $I_{w}$ years.

\subsection{Impacts of anomalous WPSH zonal location on seasonal NDVI}

The influence of climate factors on vegetation growth is the combination of precipitation, air temperature and other factors, and their impacts are different in seasons. Figure 8 shows spatial pattern of the correlation coefficients between seasonal NDVI and seasonal average air temperature and precipitation. Spring precipitation is positively correlated with NDVI in some areas of IM and NC, but negatively correlated with NDVI in eastern SC (Figure 7a). The higher spring precipitation in eastern SC is often accompanied by lower temperature corresponding to lower NDVI, so the precipitation is negatively correlated with NDVI in eastern SC. Spring temperature is positively correlated with NDVI in NC, IM, SC and northern NW (Figure 7b). Higher spring temperature favors snow melting, high soil moisture and thus vegetation growth.

Summer precipitation is negatively correlated with NDVI in some area of SC but it is positively correlated with NDVI in IM and northern NW (Figure 7c). Higher summer temperature is often accompanied by drought and heat wave, so summer temperature is negatively correlated with NDVI in most areas of IM, NW and NC, but it is positively correlated with NDVI in some areas of SC (Figure 7d).

Autumn precipitation is negatively correlated with NDVI in NW, NC and SC. Autumn temperature is positively correlated with NDVI in most areas of IM, NC and SC (Figure 7f). Higher autumn temperature prolongs vegetation's growth season to increase NDVI.

Figure 8 shows seasonal NDVI composite for low $I_{w}$ years is all greater than that composite for high $I_{w}$ years in IM, NW, NC and SC. The seasonal relationships between NDVI and climate factors can generally explain the NDVI differences between low and high $I_{w}$ years. For IM, higher spring and autumn temperature, as well as higher summer precipitation favors vegetation growth, so NDVI is greater in low $I_{w}$ years. Although NW is not in the impact areas of the East Asian monsoon, its NDVI anomalies in low and high $I_{w}$ years are consistent with those in IM. Higher spring and summer precipitation as well as higher autumn temperature can explain higher NDVI in low $I_{w}$ years for NW and NC. Higher four seasons' temperature for low $I_{w}$ years can explain the NDVI increase in SC.

\section{Conclusions}

East Asian monsoon controls the precipitation and temperature change in most areas of China, but our understanding of its relationship with vegetation is limited because of its complexity. In present study, we focus on the impacts of the WPSH which is one of the most important components of the East Asian monsoon system. We found a strong WPSH favors NDVI increase in eastern China, while a weak WPSH corresponds to a reduction in NDVI. The zonal shifts of WPSH has a profound influence on the vegetation growth in eastern and northwestern China. If WPSH is located in the west position, then the circulation pattern favors warm water vapor transportation to eastern China, which leads to significant precipitation. The westward expansion of WPSH also brings higher spring and autumn temperatures to east China, which favors vegetation growth. If WPSH is in the east position, then 
precipitation greatly decreases in eastern and northwestern China and the spring and autumn temperature are lower than the average, accompanied by decreased NDVI.

Although the changes of climate factors in an area which control vegetation growth, yet they depend on the interaction of several climate systems. Our results show WPSH explains $14 \%-23 \%$ variations of the factors which affect NDVI in northern and northwestern China, and $14 \%-16 \%$ variations of the factors which affect GPP in China. The location and intensity of WPSH are easy to identify through $500 \mathrm{hPa}$ geopotential height, and thus our results provide a simple way for the prediction of the vegetation growth trend in China.
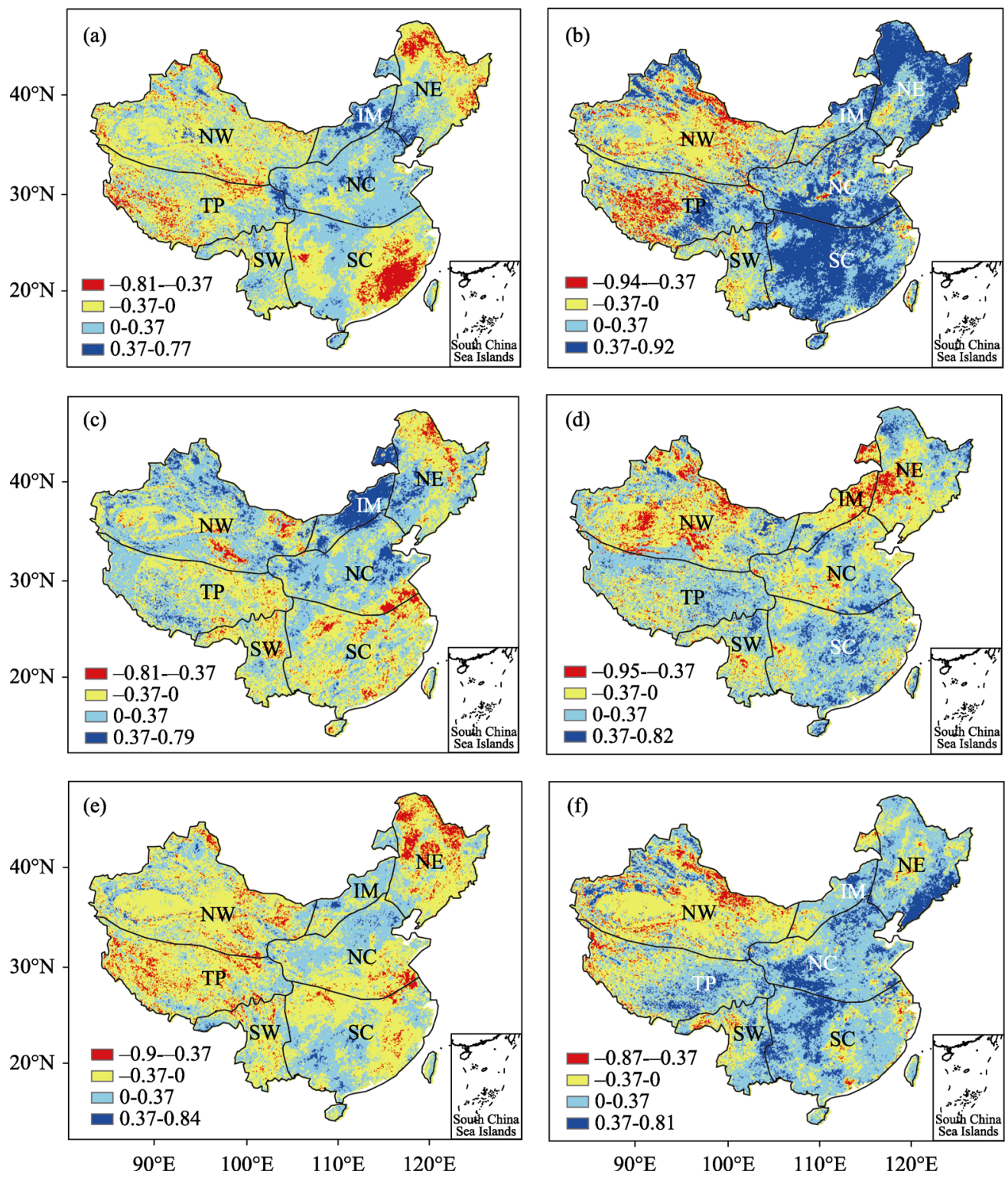

Figure 7 (a) Spatial pattern of correlation coefficient between spring precipitation and spring NDVI; (b) As (a) but for spring temperature; (c) Spatial pattern of correlation coefficient between summer precipitation and summer NDVI; (d) As (c) but for summer temperature; (e) Spatial pattern of correlation coefficient between autumn precipitation and autumn NDVI; (f) As (e) but for autumn temperature 

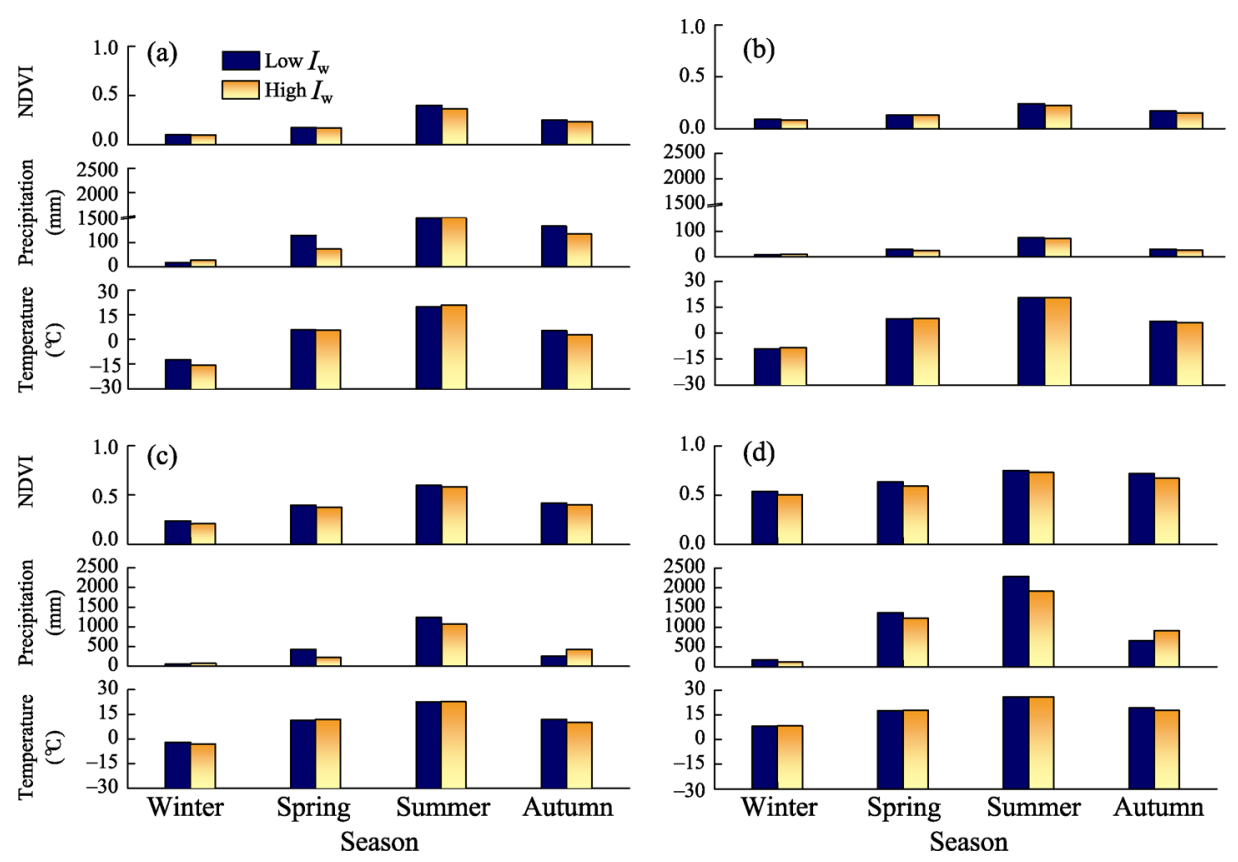

Figure 8 (a) Comparison of the seasonal mean NDVI, seasonal precipitation and seasonal mean temperature composite for low $I_{w}$ and high $I_{w}$ years for IM; (b) as (a) but for NW; (c) as (a) but for NC; and (d) as (a) but for SC

\section{References}

Anyamba A, Tucker C J, Mahoney R, 2002. From El Niño to La Niña: Vegetation response patterns over East and Southern Africa during the 1997-2000 period. Journal of Climate, 15(21): 3096-3103.

Cui Linli, Shi Jun, 2010. Temporal and spatial response of vegetation NDVI to temperature and precipitation in eastern China. Journal of Geographical Sciences, 20(2): 163-176.

Ding Mingjun, Li Lanhui, Zhang Yili et al., 2015. Start of vegetation growing season on the Tibetan Plateau inferred from multiple methods based on GIMMS and SPOT NDVI data. Journal of Geographical Sciences, 25(2): 131-148.

Fu Congbin, Wen Gang, 1999. Variation of ecosystems over East Asia in association with seasonal, interannual and decadal monsoon climate variability. Climatic Change, 43(2): 477-494.

Goswami B N, Krishnamurthy V, Annmalai H, 1999. A broad-scale circulation index for the interannual variability of the Indian summer monsoon. Quarterly Journal of the Royal Meteorological Society, 125(125): 611-633.

Guo Qiyun, 1983. The summer monsoon intensity index in East Asia and its variation. Acta Geographica Sinica, 38(3): 207-217. (in Chinese)

Holben B N, 1986. Characteristics of maximum-value composite images from temporal AVHRR data. International Journal of Remote Sensing, 7(11): 1417-1434.

Huang Jiayou, Wang Shaowu, 1985. Investigations on variations of the Subtropical High in the Western Pacific during historic times. Climatic Change, 7(4): 427-440.

Hutchinson M F, 1989. A new objective method for spatial interpolation of meteorological variables from irregular networks applied to the estimation of monthly mean solar radiation, temperature, precipitation and windrun. CSIRO Division of Water Resources, 89(5): 95-104.

Jarlan L, Tourre Y M, Mougin E et al., 2005. Dominant patterns of AVHRR NDVI interannual variability over the Sahel and linkages with key climate signals (1982-2003). Geophysical Research Letters, 32(4): 353-368.

Ji Jinjun, Huang Mei, Li Kerang, 2008. Prediction of carbon exchanges between China terrestrial ecosystem and atmosphere in 21 st century. Science in China Series D: Earth Sciences, 51(6): 885-898.

Jiang Chao, Xu Yongfu, Ji Jinjun, 2013. Response of the summer terrestrial carbon cycle in the East Asian mon- 
soon region to East Asian monsoon. Climatic \& Environmental Research, 18(3): 329-341. (in Chinese)

Jiang Xingwen, Li Yueqing, Yang Song et al., 2011. Interannual and interdecadal variations of the South Asian and western Pacific subtropical highs and their relationships with Asian-Pacific summer climate. Meteorology and Atmospheric Physics, 113(3): 171-180.

Kalnay E, Kanamitsu M, Kistler R et al., 1996. The NCEP/NCAR 40-year reanalysis project. Bulletin of the American Meteorological Society, 77(3): 437-472.

Li Jing, Fan Ke, Xu Zhiqing, 2016. Links between the late wintertime North Atlantic Oscillation and springtime vegetation growth over Eurasia. Climate Dynamics, 46(3/4): 987-1000.

Li Jianping, Zeng Qingcun, 2002. A unified monsoon index. Geophysical Research Letters, 29(8): 115-1-115-4.

Li Yueyue, Huang Mei, Ji Jinjun et al., 2015. Studies on the response mechanisms of vegetation net primary productivity in Chinese monsoon region to the variations of East Asian summer monsoon. Climatic \& Environmental Research, 20 (5): 544-554. (in Chinese)

Li Zuotao, Kafatos M, 2000. Interannual variability of vegetation in the United States and its relation to El Niño/Southern Oscillation. Remote Sensing of Environment, 71(3): 239-247.

Liu Yimin, Wu Guoxiong, 2004. Progress in the study on the formation of the summertime subtropical anticyclone. Advances in Atmospheric Sciences, 21(3): 322-342.

Los S O, Collatz G J, Bounoua L et al., 2001. Global interannual variations in sea surface temperature and land surface vegetation, air temperature, and precipitation. Journal of Climate, 14(7): 1535-1549.

Lu Riyu, 2002. Indices of the summertime western North Pacific subtropical high. Advances in Atmospheric Sciences, 19(6): 1004-1028.

Nicholson S E, Tucker C J, Ba M B, 2010. Desertification, drought, and surface vegetation: an example from the West African Sahel. Bulletin of the American Meteorological Society, 79(5): 815-829.

Piao Shilong, Fang Jingyun, 2003. Seasonal changes in vegetation activity in response to climate changes in China between 1982 and 1999. Acta Geographica Sinica, 58(1): 119-125. (in Chinese)

Piao Shilong, Fang Jingyun, Zhou Liming et al., 2003. Interannual variations of monthly and seasonal normalized difference vegetation index (NDVI) in China from 1982 to 1999. Journal of Geophysical Research Atmospheres, 108(D14): ACL 1-1.

Sun Shuqing, Ying Ming, 1999. Subtropical high anomalies over the western Pacific and its relations to the Asian monsoon and SST anomaly. Advances in Atmospheric Sciences, 16(4): 559-568.

Tucker C J, 1979. Red and photographic infrared linear combinations for monitoring vegetation. Remote Sensing of Environment, 8(2): 127-150.

Wang Bin, Fan Zhen, 1999. Choice of South Asian summer monsoon indices. Bulletin of the American Meteorological Society, 80(4): 629-638.

Webster P J, Yang Song, 1992. Monsoon and ENSO: Selectively interactive systems. Quarterly Journal of the Royal Meteorological Society, 118(507): 877-926.

Yang Hui, Sun Shuqing, 2003. Longitudinal displacement of the subtropical high in the western Pacific in summer and its influence. Advances in Atmospheric Sciences, 20(6): 921-933.

Zhang Jiahua, Fu Congbin, 2002. Research on the response of China eastern ecosystem to East Asian monsoon by using leaf area index through remote sensing inversion. Progress in Natural Science, 12(10): 1098-1102. (in Chinese)

Zhang Jie, Zhang Qiang, Yang Lihua et al., 2006. Seasonal characters of regional vegetation activity in response to climate change in West China in recent 20 years. Journal of Geographical Sciences, 16(1): 78-86.

Zhang Xuezhen, Dai Junhu, Ge Quansheng, 2013. Variation in vegetation greenness in spring across eastern China during 1982-2006. Journal of Geographical Sciences, 23(1): 45-56.

Zhou Tianjun, Yu Rucong, 2005. Atmospheric water vapor transport associated with typical anomalous summer rainfall patterns in China. Journal of Geophysical Research Atmospheres, 110(8): D08104.

Zhou Tianjun, Yu Rucong, Zhang Jie et al., 2009. Why the western Pacific subtropical high has extended westward since the late 1970s. Journal of Climate, 22(8): 2199-2215.

Zhou Wei, Gang Chengcheng, Chen Yizhao et al., 2014. Grassland coverage inter-annual variation and its coupling relation with hydrothermal factors in China during 1982-2010. Journal of Geographical Sciences, 24(4): 593-611. 